\title{
Statistical Analysis of Properties of Compact Yarn Produced from Different Process
}

\author{
Toufiqua Siddiqua, Assistant Professor \\ Md. Alimur Reza, Undergraduate Student \\ Habiba Altaf, Undergraduate Student \\ Department of Yarn Engineering, \\ Bangladesh University of Textiles, Dhaka, Bangladesh
}

Doi: 10.19044/esj.2019.v15n12p150 URL:http://dx.doi.org/10.19044/esj.2019.v15n12p150

\begin{abstract}
Compact spinning system is a great modification of ring spinning system. It brings a revolution over ring spinning system in case of hairiness and strength of yarn. In this paper, three yarn of "34's Ne" count was produced in three different spinning systems termed as conventional Ring, Suessen Elite compact, and RoCoS (Rotorcraft) compact spinning system. During processing, all the processing parameters and the environment were kept the same in the case of the compact spinning system. Yarn properties are then tested with Uster Evenness Tester 6 and Mesdan strength tester. Statistical analysis like t-test paired two samples for means for all the properties of two compact yarns such as unevenness percentage, imperfection index, hairiness, tenacity, elongation, and count strength product were performed using Microsoft Excel 2013. Suessen Elite compact spinning system shows good results than another compact spinning system. It was found from the statistical analysis that there is no significant difference in the maximum properties of two compact spinning systems, especially in hairiness and tenacity, as these two properties are crucial in the compact spinning system.
\end{abstract}

Keywords: Compact spinning, Suessen Elite, Rotorcraft, t-test, yarn properties

\section{Introduction}

For the production of textiles and apparel, the first and the most significant process used is spinning which converts the mass of fibres into long spun yarn, and this is much suitable for weaving and knitting. Ring spinning system is the greatest versatile spinning system to produce yarn from fibre nowadays. Nevertheless, there is a problem in ring spinning system 
because it has a spinning triangle which creates hairiness difficulties. In spinning, triangle tension varies on fibre which depends on the position of the fibre. A fibre in center position is able to stay in less tension than the fibres which remains alongside in transversal part. Spinning procedure has to be applied to reduce the hairiness in the spun yarn so that the appearance of the finished product will appear better. As a result of this, the price of the process increases (Xinjin Liu \& Xingfeng Wang, 2017, p.238-250; Bobajonov, Yuldashev, Gafurov, \& Gofurov, 2017, p.254). The yarn obtained from ring spinning system is considered to be the best among the other spun yarn. However, practically it is not good enough. Based on the test result of evenness tester especially hairiness value, it can be found that yarn body contains a certain amount of protruding fibres. This is because of some edge fibres that escaped from the yarn body which are disorderly arranged during the twisting of ribbon fibres delivered from the front nip. These projecting fibres have less or no contribution in yarn strength (Akshay Kumar, Ishtiaque \& Salhotra, 2003, p.15-21). Compact spinning system is a modification of a conventional ring spinning system which provides major advantages both in short and long staple spinning system. This spinning technology launched its journey at ITMA-Paris in 1999 (Pinar Çelik \& Hüseyin Kadoğlu, 2004, p.48). The spinning principle of compact spinning involves addition of compacting zone in a ring frame and drafted ribbon of fibre from the front roller which are condensed by negative pressure airflow of machinery. This is done so that the spinning triangle of ring spinning is reduced. Different numbers of designs are offered by different machine manufacturers in recent times but all of them use almost the same principle, which specifically congregates the fibre ribbon at the end of the drafting region pneumatically or in another way (Xichang Zhang, Haixia Zhang, \& Longdi Cheng, 2013, p.288-292). The major advantages of compact spinning are that it reduces hairiness. On the other hand, it increases the strength of yarn which is much suitable for weaving and knitting process, and this produces a better quality of fabric (Jerzy Czekalski, Danuta Cyniak, Tadeusz Jackowski, \& Karol Sieradzki, 2007, p.62).

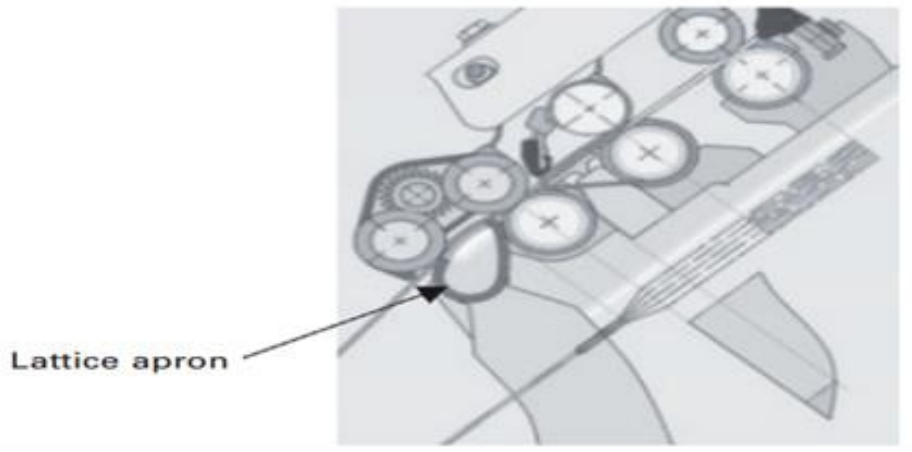

Figure 1(a). Suessen Elite spinning system (Gowda, 2010, p.56-90) 

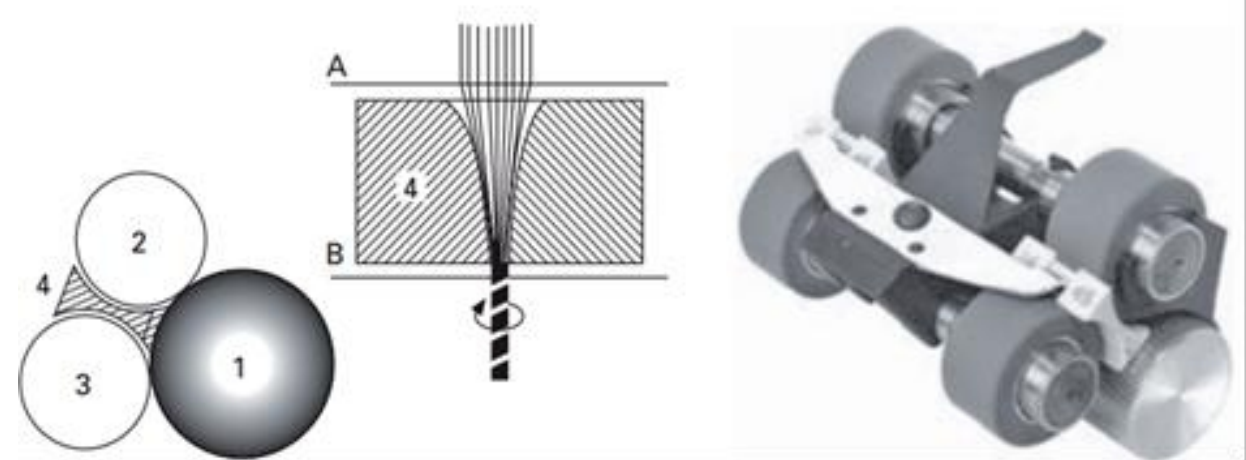

Figure 1(b). RoCoS compact spinning system and devices (Gowda, 2010, p.56-90)

(1 - Cylinder, 2 - Front roller, 3 - Delivery roller, 4 - Magnetic compactor, A \& BClamping line)

\section{Materials and Method}

CIS cotton fiber was taken as a raw material for the production of yarn. Different fibre properties were tested by using the High Volume Instrument (HVI) and Advanced Fibre Information System (AFIS). These two machines are very crucial for knowing the properties of fibres. Also, all the fibre properties test can be performed through these machines. Samples are conditioned by testing atmospheric condition before the test. Therefore, the test properties of those machines are given below:

Table 1. Fibre properties

\begin{tabular}{|c|c|c|c|}
\hline \multicolumn{2}{|c|}{ HVI } & \multicolumn{2}{c|}{ AFIS } \\
\hline Properties & Values & Properties & Values \\
\hline SCI & 122 & NEP (Cnt/g) & 221 \\
\hline Moisture (\%) & 6.9 & NEP Size (um) & 728 \\
\hline Mic Value & 4.44 & SCN (Cnt/g) & 25 \\
\hline Maturity Ratio & 0.87 & SCN (um) & 1249 \\
\hline UHML (mm) & 28.83 & SFC (\%) & 7.5 \\
\hline UI (\%) & 81.3 & UQL (mm) & 30.5 \\
\hline SF (\%) & 7.9 & $5 \%(m m)$ & 34.7 \\
\hline Strength (GPT) & 32.6 & Fineness (mtex) & 167 \\
\hline Elongation (\%) & 6 & IFC (\%) & 7.3 \\
\hline
\end{tabular}

The yarn was produced in pure ring spinning system and two compact spinning systems named Suessen Elite and Rotorcraft system which is used to produce yarn in short staple spinning. Yarn count of " 34 's $\mathrm{Ne}$ " $\mathrm{CH}$ (Combed Hosiery) was produced in three spinning systems. Roving count of $0.80 \mathrm{Ne}$ was kept during the processing of material. The same roving was fed to each spindle of ring frame so that the variation can remain less. Additionally, all samples are produced with the same parameters such as traveller no., draft, 
spindle speed, no. of twist per inch, etc. in two compact spinning systems. Ring frame parameters also are given in Table 2 below.

Table 2. Processing parameters of the ring frame

\begin{tabular}{|c|c|c|c|}
\hline Parameters & Ring & Suessen & Rotorcraft \\
\hline Break Draft & 1.15 & 1.15 & 1.15 \\
\hline Total Draft & 43 & 43 & 43 \\
\hline Spindle Speed & 16500 & 16000 & 16000 \\
\hline TPI & 21.72 & 19.96 & 19.96 \\
\hline Traveller No. & $4 / 0$ & $3 / 0$ & $3 / 0$ \\
\hline
\end{tabular}

After collection of the sample from ring frame, it was wound on the winding machine. The speed of winding was $1500 \mathrm{~m} / \mathrm{min}$. The yarn packages were conditioned by testing atmospheric conditions. Different properties of yarn such as evenness properties and hairiness were carried out in Uster Evenness Tester 6. Furthermore, test speed of evenness tester was $400 \mathrm{~m} / \mathrm{min}$ and the test time took 1 minute for each test. Other important properties like tenacity, elongation, and count strength product (CSP) was performed with Mesdan strength tester. Sample length and clamp speed was $645 \mathrm{~mm}$ and 500 $\mathrm{mm} /$ minute respectively in Mesdan strength tester. Afterwards, all test results were used to evaluate the statistically significant difference between two compact spinning systems. Paired t-test is done for all test results from two testing machines in Microsoft Excel 2013.

Table 3. Yarn properties of different spinning systems

\begin{tabular}{|c|c|c|c|c|c|c|}
\hline $\begin{array}{c}\text { Different } \\
\text { Systems }\end{array}$ & $\begin{array}{c}\mathbf{U}_{\mathbf{m}} \\
(\mathbf{\%})\end{array}$ & $\begin{array}{c}\text { Imperfection } \\
\text { Index (-) }\end{array}$ & $\begin{array}{c}\text { Hairiness } \\
(-)\end{array}$ & $\begin{array}{c}\text { Tenacity } \\
(\mathbf{c N / t e x})\end{array}$ & $\begin{array}{c}\text { Elongation } \\
(\mathbf{\%})\end{array}$ & $\begin{array}{c}\mathbf{C S P} \\
(\mathbf{N e} \text { *lb) }\end{array}$ \\
\hline Ring & 10.15 & 154 & 6.33 & 1945.06 & 6.09 & 2582.28 \\
\hline $\begin{array}{c}\text { Suessen } \\
\text { Elite }\end{array}$ & 8.9 & 88.3 & 4.84 & 2238.65 & 6.53 & 2972.05 \\
\hline Rotorcraft & 9.15 & 98.3 & 4.36 & 1965.76 & 6.05 & 2609.76 \\
\hline
\end{tabular}

\section{Results and Discussions \\ Yarn Unevenness Results}

Unevenness is a statistical parameter to express the evenness properties of the yarn. It is an important property of yarn which helps the spinners to take decision for the assumption of the quality of yarn. From Figure 2 , it is observed that unevenness percentage of Suessen compact spinning system is less than that of Rotorcraft compact and Ring spinning system. This is due to the fact that the air suction through perforated lattice apron in Suessen is better than Rotorcraft mechanical magnetic attachment. As a result, compacting of fibre is good and unevenness properties are better. 


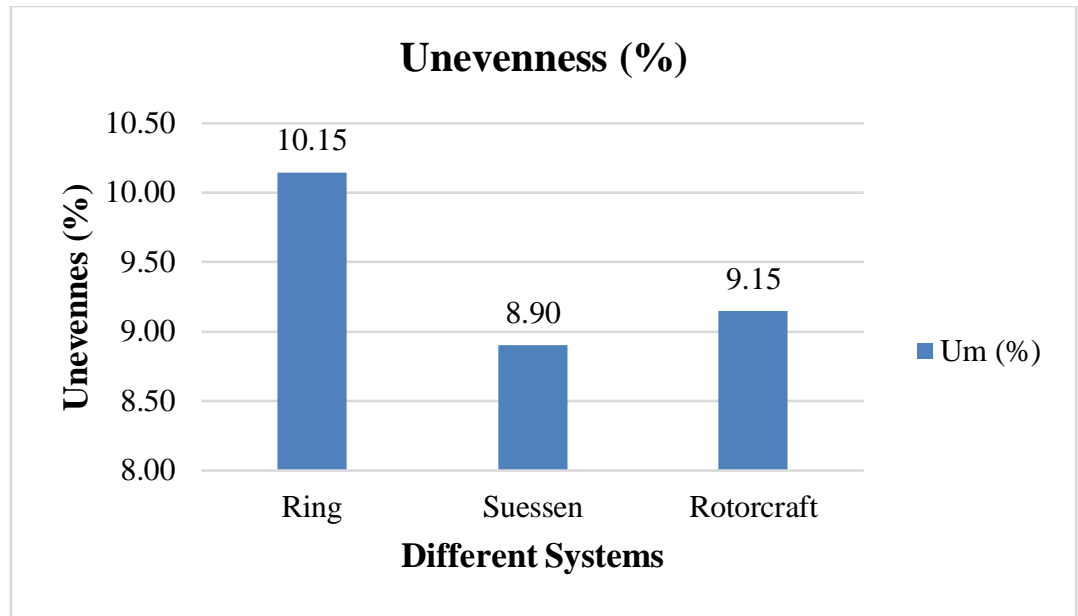

Figure 2. Unevenness properties of the yarn

\section{Yarn Imperfection Results}

Yarn imperfection is one of the important properties, which has a visual effect on fabric and leads to a satisfactory level. Here, imperfection means a total number of thick, thin, and neps per kilometer of yarn. Imperfection index is the highest in Ring yarn, and it is also higher in Rotorcraft compact yarn compared to Suessen compact yarn. A possible explanation might be that the level of compacting in Rotorcraft is less than Suessen. This is due to the air passing arrangement in Suessen and the magnetic force developed in RoCoS system.

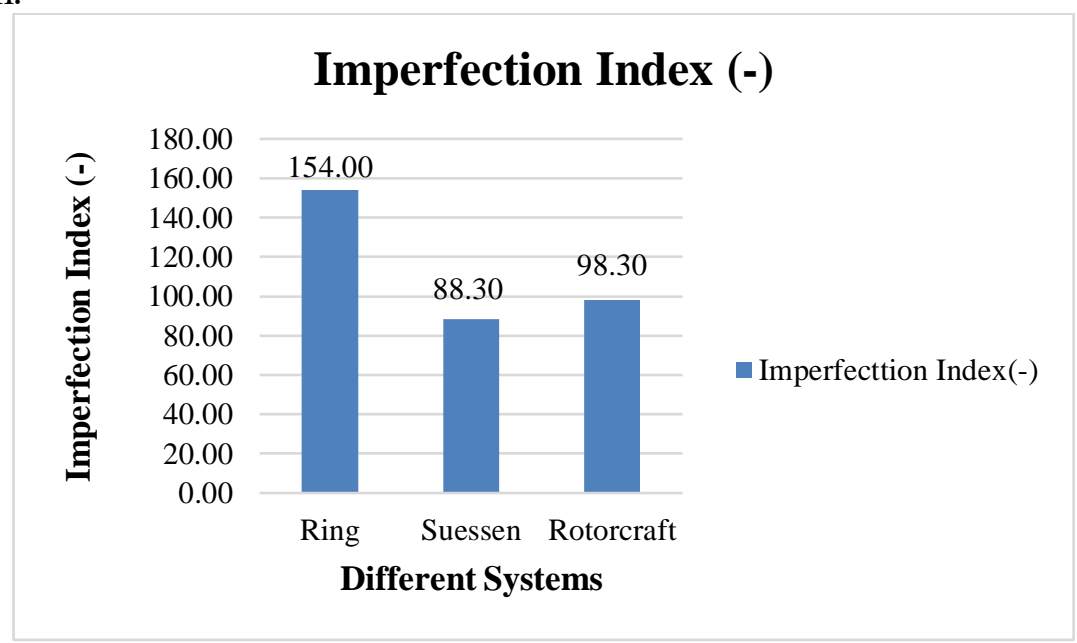

Figure 3. Imperfection index in yarn

\section{Yarn Hairiness Results}

Hairiness is a significant property of yarn which has a great influence in the appearance on fabric, particularly after dyeing or printing. Therefore, 
compact spinning system is developed specially for reducing the hairiness value of yarn which is prominent in conventional ring spun yarn. It is seen from Figure 4 that hairiness value is less in Rotorcraft than Suessen and Ring yarn. It may be assumed then that Rotorcraft compact spinning system works on mechanical magnetic compacting principle. Thus, it may be possible that due to the creation of magnetic field at the end of drafting zone, the magnetic force incorporated properly in the projecting fibre ends in the main body of the yarn. This is not good in air suction principle which is used in Suessen Elite spinning system. Also, a ring has no attachment in it at the end of the main drafting zone so that hairiness value remains at the highest position.

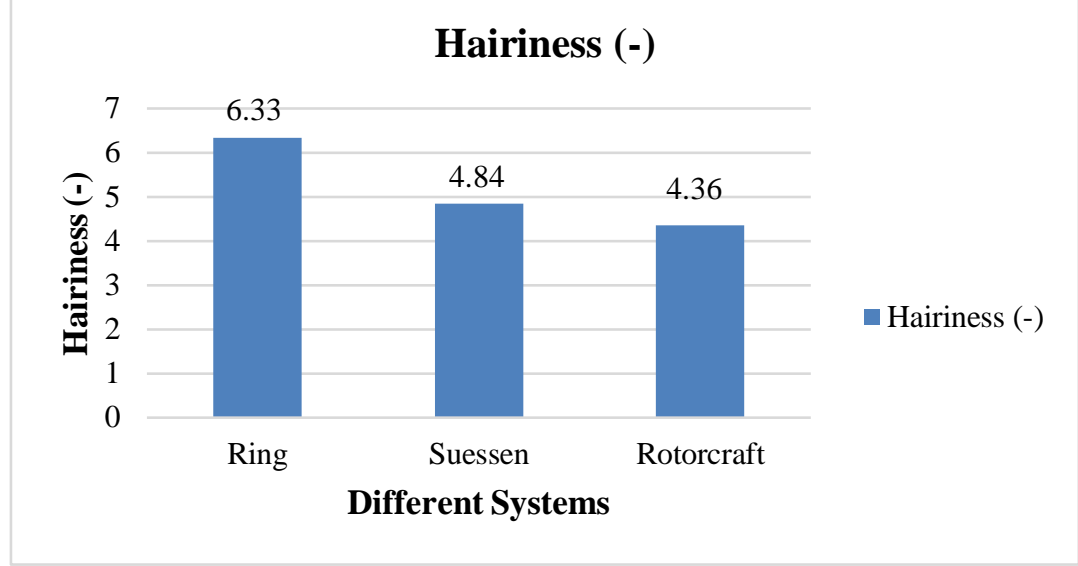

Figure 4. Hairiness of yarn

\section{Yarn Tenacity, Elongation and CSP Results}

Tenacity, elongation, and count lea-strength product values are shown in Figure 5, 6, and 7 respectively. In all three cases, values are highest in Suessen than Rotorcraft and Ring spinning system. The probable enlightenment is that air suction condenses the fibres more uniformly and in a parallel way than magnetic packing. The air suction passes through the fibres so that there is a possibility of obtaining a scope of good uniformity and parallelization of fibres in Suessen. Consequently, it may be predicted that the magnetic compacting system integrates the fibre edge only into yarn body but not evenly. As a result, strength value is less. 


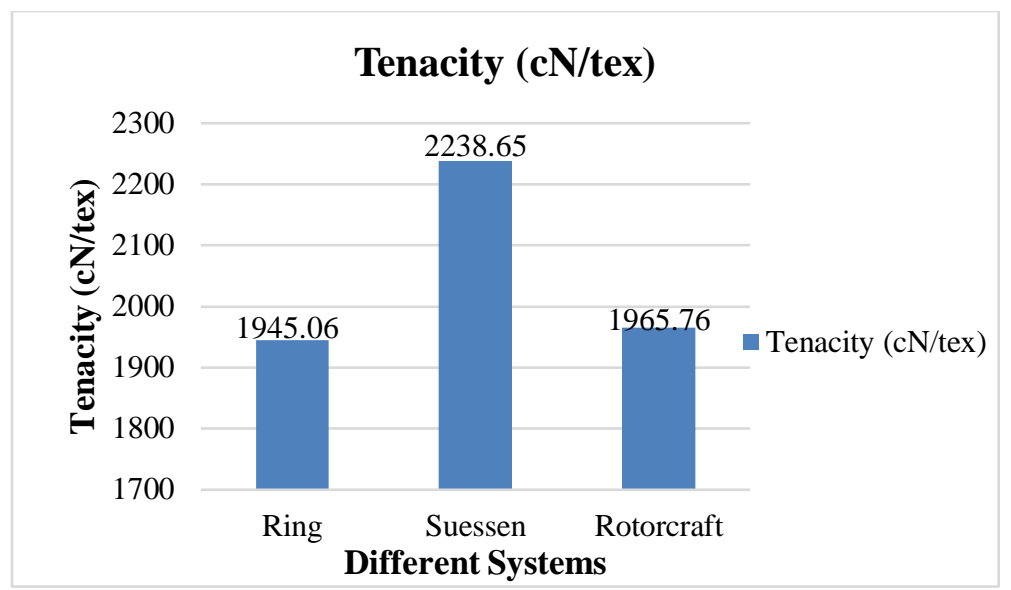

Figure 5. Tenacity of yarn

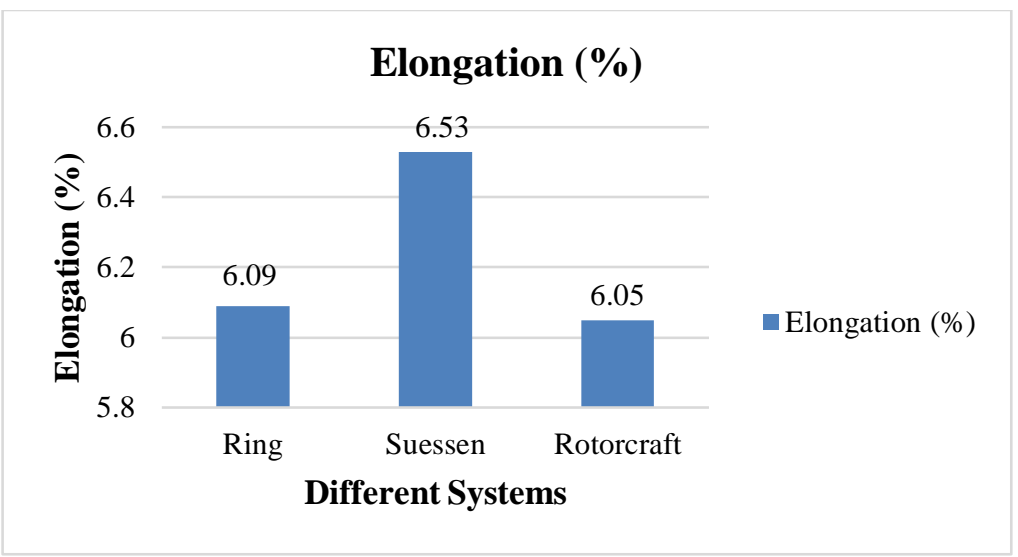

Figure 6. Elongation of yarn

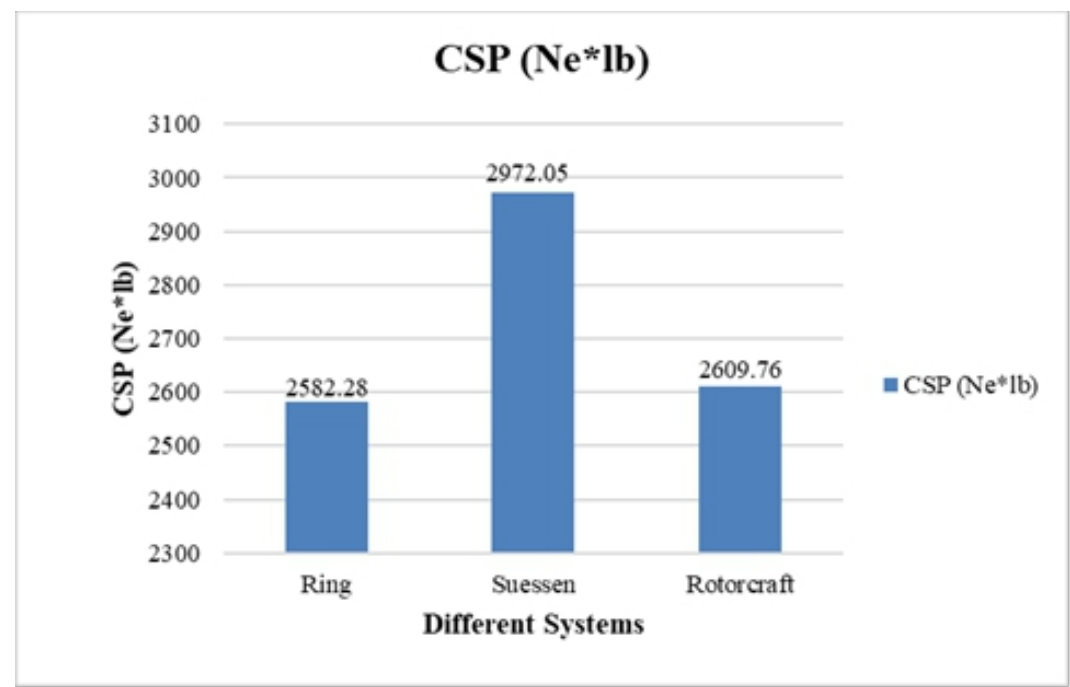

Figure 7. CSP of yarn 


\section{Statistical Analysis}

A Pearson's correlation was run to determine the relationship between parameters of Suessen and Rotorcraft values. The Pearson correlation coefficient value of -0.188 (For Hairiness) and -0.233 to -0.382 (For Unevenness, imperfection index, tenacity, elongation, and CSP) confirms that it is apparent to be a very weak correlation among the properties of two systems respectively. However, there is the need to perform a significance test to decide whether, based upon this sample, there is any or no evidence to suggest that linear correlation is present in the population.

To do this, the null hypothesis, $\mathrm{H}_{0}$, which states that there is no correlation in the population is tested against the alternative hypothesis, $\mathrm{H}_{1}$, which states that there is a correlation. The data indicates which of these opposing hypotheses is most likely to be true. It can thus express this test as:

$$
\begin{aligned}
& \mathrm{H}_{0}: \rho=0 \\
& \mathrm{H}_{1}: \rho \neq 0
\end{aligned}
$$

The results showed that there was a very weak correlation in the case of hairiness and weak correlation of other parameters between Suessen and Rotorcraft spinning system.

From Table 4 , it is seen that $\mathrm{t}$ statistics value exceeds the $\mathrm{t}$ critical onetail and $t$ critical two-tail value for all the parameters except imperfection index. This means that t-test is significant and the two groups are statistically significantly different. On the other hand, imperfection index has no statistically significant difference between the values of two systems. The pvalue for one-tail and a two-tail test is less than 0.05 for all the parameters except Imperfection Index. That implies that there is no significant difference in the means of each sample. The p-value in the case of imperfection index exceeds the significant levels which indicate that there is a significant difference between two spinning systems.

Table 4. t-test: paired two samples for means

\begin{tabular}{|c|c|c|c|c|c|c|}
\hline Parameters of t-test & $\mathbf{U}_{\mathbf{m}}(\boldsymbol{\%})$ & $\begin{array}{c}\text { Imperfection } \\
\text { Index (-) }\end{array}$ & $\begin{array}{c}\text { Hairiness } \\
(-)\end{array}$ & $\begin{array}{c}\text { Tenacity } \\
(\mathbf{c N / t e x})\end{array}$ & $\begin{array}{c}\text { Elongation } \\
(\mathbf{\%})\end{array}$ & $\left.\begin{array}{c}\text { CSP } \\
(\mathbf{N e}\end{array} \mathbf{~} \mathbf{l b}\right)$ \\
\hline Pearson Correlation & -0.233 & -0.382 & -0.188 & -0.312 & -0.351 & -0.312 \\
\hline $\begin{array}{c}\text { Hypothesized Mean } \\
\text { Difference }\end{array}$ & 0 & 0 & 0 & 0 & 0 & 0 \\
\hline df & 9 & 9 & 9 & 5 & 5 & 5 \\
\hline t Stat & -3.173 & -0.967 & 3.998 & 7.544 & 3.826 & 7.544 \\
\hline P(T<=t) one-tail & 0.006 & 0.180 & 0.002 & 0.000 & 0.006 & 0.000 \\
\hline t Critical one-tail & 1.833 & 1.833 & 1.833 & 2.015 & 2.015 & 2.015 \\
\hline P(T<=t) two-tail & 0.011 & 0.359 & 0.003 & 0.001 & 0.012 & 0.001 \\
\hline t Critical two-tail & 2.262 & 2.262 & 2.262 & 2.571 & 2.571 & 2.571 \\
\hline
\end{tabular}




\section{Conclusion}

Suessen Elite compact yarn properties show good results than Rotorcraft or RoCos compact yarn. The reason behind this is due to their condensing principle. Suessen uses air suction whereas Rotorcraft uses magnetic condensing. All the results of evenness tester except hairiness are better in Suessen. Due to the strong magnetic force in Rotorcraft, protruding fibres are integrated into the main body of yarn so that this result is better in this system. Tenacity, elongation, and CSP results of yarn produced from Suessen Elite system are much better than Rotorcraft because of uniformity of air current which passes through the fibre. The compacting intensity is even and parallelization of fibre is more. All properties of ring spun yarn demonstrate badly because of an absence of condensing attachment. From the results of paired t-test, it can be said that p-value for one-tail and the two-tail test is less than 0.05 for all the parameters except imperfection index. This indicates that there is no statistically significant difference between two compacting spinning systems.

\section{References:}

1. Akshay, K., Ishtiaque, SM., \& Salhotra, KR. (2003). Compact Spinning -A Critical Review, 2003 ASME International Mechanical Engineering Congress, Washington, D.C., November 15-21.

2. Bobajonov, HT., Yuldashev,JK., Gafurov, JK., \& Gofurov, K. (2017). The arrangement of the fibers in the yarn and effect on its strength. 17th World Textile Conference AUTEX 2017- Textiles Shaping the Future IOP Publishing IOP Conf. Series: Materials Science and Engineering 254 (2017).

3. Gowda, RVM. (2010). Technical Textile Yarns: Advances in yarn spinning and texturising. (pp.56-90), North America, Woodhead Publishing Limited.

4. Jerzy Czekalski, Danuta Cyniak, Tadeusz Jackowski, \& Karol Sieradzki (2007). Quality of Wool-Type Compact Yarns from Twisted and Rubbed Roving. FIBRES \& TEXTILES in Eastern Europe, 15, 62.

5. Pinar Çelik \& Hüseyin Kadoğlu (2004). A Research on the Compact Spinning for Long Staple Yarns. FIBRES \& TEXTILES in Eastern Europe, 12, 48.

6. Xinjin Liu \& Xingfeng Wang (2017). Research on qualities of compact spun silk yarn. International Journal of Clothing Science and Technology, 29, 238-250.

7. Xichang Zhang, Haixia Zhang, \& Longdi Cheng (2013). Effect of Negative Pressure on Yarn Quality in Compact Spinning with Inspiratory Groove. Advanced Materials Research, 627, 288-292. 